$$
\begin{aligned}
& \text { CONF }-961040-26 \\
& L A-U R=-97-736
\end{aligned}
$$

\title{
ELECTROPHORETIC NMR MEASUREMENTS OF LITHIUM TRANSFERENCE NUMBERS IN POLYMER GEL ELECTROLYTES
}

\author{
Hongli Dai, Sharon Sanderson, John Davey, Francisco Uribe, and Thomas A. \\ Zawodzinski Jr. \\ Electronics Materials and Device Research Group \\ Los Alamos National Laboratory \\ Los Alamos, NM 87545
}

\begin{abstract}
We describe here our application of electrophoretic NMR (ENMR) to the determination of transference numbers of lithium ions in polymer gel electrolytes. Two types of polymer gel electrolytes were selected for this study: PAN /PC/EC/LiX and Kynar/PC/LiX. Results obtained for the two types of gels are compared and the effects of anion, polymer-ion interactions and ion-ion interactions on lithium transference numbers are discussed. Significant differences in the behavior of transference numbers with salt concentration are observed for the two types of gels. This may be due to the extent of interaction between the polymer and the ions. Implications for solid polymer electrolytes are discussed.
\end{abstract}

\section{INTRODUCTION}

Polymer gel electrolytes are of increasing interest for plastic lithium batteries largely because of their high room temperature conductivity $(1,2)$. Several studies have probed their conductivity and electrochemical stability but very little work has been done related to lithium transference numbers. Lithium ion transference numbers, the net number of Faradays carried by lithium upon the passage of 1 Faraday of charge across a cell, are key figures of merit for any potential lithium battery electrolytes. Non-unity lithium transference numbers lead to concentration polarization in cells employing those electrolytes. However, reliable methods for determining $T_{L i}$ have proven to be difficult to come by, as discussed by Vincent and co-workers (3). In spite of this, a substantial amount of polymer electrolyte development has been carried out with the aim of increasing lithium transference numbers. Transference numbers are also necessary quantities for modeling of electrolyte behavior in batteries.

The classical Hittorf method provides a rigorous method for measuring transference numbers, but this method is difficult to apply to polymeric systems. The

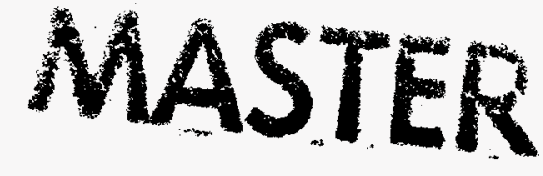




\section{DISCLAIMER}

This report was prepared as an account of work sponsored by an agency of the United States Government. Neither the United States Government nor any agency thereof, nor any of their employees, makes any warranty, express or implied, or assumes any legal liability or responsibility for the accuracy, completeness, or usefulness of any information, apparatus, product, or process disclosed, or represents that its use would not infringe privately owned rights. Reference herein to any specific commercial product, process, or service by trade name, trademark, manufacturer, or otherwise does not necessarily constitute or imply its endorsement, recommendation, or favoring by the United States Government or any agency thereof. The views and opinions of authors expressed herein do not necessarily state or reflect those of the United States Government or any agency thereof. 


\section{DISCLAMMER}

Portions of this document may be illegible in electronic image products. Images are produced from the best available original document. 
validity of many proposed electrochemical methods is conditional: they are valid when the only mobile species are free cations and anions. As a result, their applicability is limited. In particular, they are questionable for most polymer electrolytes, in which extensive ion aggregation is present even at low salt concentrations. Olsen et al (4) reported Hittorf measurements in plasticized, cross-linked PEO hybrid electrolytes. Their results indicate increasing transference numbers with salt concentration but the scatter in the data is large and the trend is weak.

We have developed another approach to the determination of transference numbers. We use electrophoretic NMR (ENMR), a method in which the net mobility or flow velocity of a marker nuclei is followed, to study transference. We described our initial work in a recent publication (5). Rather than measuring the results of long-term polarization by sampling concentrations in the electrolyte, we directly probe the ion mobilities underlying the development of the concentration profile on a time scale of a few seconds for each signal average. This is accomplished by monitoring, using NMR, the evolution of signal phase relative to an initial reference phase during the passage of current in an electrophoretic cell in the NMR probe. The method is conceptually simple and allows the rapid and accurate determination of transference numbers. Furthermore, we can show explicitly that the method is strictly valid regardless of the extent of the ion association (we will present a proof of this point in a later paper). Therefore, the ENMR method is promising for the study of transference in polymeric electrolyte systems.

Here we present and discuss some of our recent results on polymer gel electrolytes. This represents the first real application of the ENMR method we developed, as the systems under study are either used or considered for use in lithium plastic batteries. The two systems are (poly(acrylonitrile) and Kynar based respectively. Kynar ${ }^{\circledR}$ (Elf Atochem) is a block copolymer of hexafluoropropene and vinylidene fluoride. The plasticizers in PAN based electrolytes contain both propylene carbonate(PC) and ethylene carbonate (EC), while the plasticizer in Kynar based electrolytes is propylene carbonate only. LiX refers to any one of the following lithium salt: $\mathrm{LiClO}_{4}, \mathrm{LiCF}_{3} \mathrm{SO}_{3}$ and $\mathrm{Li}\left(\mathrm{CF}_{3} \mathrm{SO}_{2}\right)_{2} \mathrm{~N}$. Both electrolytes have room temperature conductivity on the order of $10^{-3} \mathrm{Scm}^{-1}$. The structure of PAN gel electrolytes is a matter of controversy (6): opinions are divided the strength of lithium interactions with the nitrile group in PAN. However, it is undoubtedly the case that the nitrile moiety interacts to some extent with the lithium and influences its mobility. For the Kynar gel electrolytes, however, it is generally agreed that the lithium transport is decoupled from the polymer. This stems from the fact that no functional group in Kynar could interact with lithium significantly. One purpose of this study is to compare lithium transference number behavior in the two systems. 


\section{EXPERIMENTAL}

Materials.

PAN (Polysciences, MW $=150,000$ ) was dried under a vacuum at $60{ }^{\circ} \mathrm{C}$ for 24 hours before use. Kynar (Elf Atochem, grade 2822) was used as received. PC(Aldrich) and $\mathrm{EC}$ (Aldrich) were distilled. $\mathrm{LiCF}_{3} \mathrm{SO}_{3}$ (Aldrich) was dried before use. $\mathrm{LiClO}_{4}$ (Aldrich) and $\mathrm{Li}\left(\mathrm{CF}_{3} \mathrm{SO}_{2}\right)_{2} \mathrm{~N}(3 \mathrm{M})$ were used as received.

Sample Preparation

All sample preparation was carried out in an argon-filled dry box (moisture $<1$

$\mathrm{ppm}$ ). Solutions were prepared by dissolving a lithium salt of interest in the plasticizer. Polymers were then add to the salt solution. The mixture is then heated to $100-120^{\circ} \mathrm{C}$ on a hot plate while stirring until a clear, homogeneous solution forms. The hot gel solution, free of gas bubbles, was cast into glass tubes (i.d. $10 \mathrm{~mm}, 5.5 \mathrm{~cm}$ in length). The ENMR cell was then assembled by sealing the sample between two Platinum mesh electrodes with O-rings and insert the sealed ENMR cell into a homebuilt NMR probe head. The probe head was then taken out of the dry box and installed into a commercial (Bruker) NMR probe.

\section{Transference Number Measurement.}

The experiments were conducted on a Bruker AMX400 spectrometer with ${ }^{7} \mathrm{Li}$ Larmor frequency of $155.5 \mathrm{MHz}$. Electric field or current pulses are delivered by a Keithely source-measure unit triggered by the NMR computer. As discussed in a separate paper in this proceeding (7), the signal-to-noise ratio of an ENMR experiment of this type depends on, besides salt molarity and sample volume, the ${ }^{7} \mathrm{Li}$ spin-lattice relaxation time and the Li diffusion coefficients. For the gel electrolytes under study at $30{ }^{\circ} \mathrm{C}$, the spin-lattice relaxation time is on the order of 600 to $1000 \mathrm{~ms}$, and the diffusion coefficients are on the order of $10^{-7} \mathrm{~cm}^{2} \mathrm{~s}^{-1}$. These values are in a range for which we will be able to detect the migration of $\mathrm{Li}$, and thus measure the transference numbers with sufficiently high signal-to-noise ratio. Typical experimental parameters include: cell currents $I=20$ to $100 \mathrm{~mA}, D=600$ to $1000 \mathrm{~ms}, \mathrm{~d}=5 \mathrm{~ms}$, and $\mathrm{G}=20$ Gauss $/ \mathrm{cm}$. We point out that for the gel systems, only a relative small magnetic gradient (G) is needed. For solid polymer electrolytes, high G NMR probes might be required.

\section{Salt Concentration Measurements.}

The salt concentrations in the gel electrolytes were measured with a spin-echo NMR microscopy method (8). This imaging technique generates images whose pixel intensity is proportional to the local salt content. We used $1 \mathrm{M} \mathrm{LiCl}$ aqueous solution as the concentration reference. The gel electrolyte of interest is imaged with the reference 
solution. The salt concentration of the gels is derived from the gel/solution image intensity ratio and the known reference solution salt concentration.

\section{RESULTS AND DISCUSSION}

\section{Anion Size Effects on Li Transference Numbers.}

There has been a large amount of work devoted to designing and identifying the optimum salt for lithium polymer electrolytes. The desired properties include safety, electrochemical stability, high conductivity and high $\mathrm{Li}$ transference numbers. $\mathrm{Li}\left(\mathrm{CF}_{2} \mathrm{SO}_{2}\right)_{2} \mathrm{~N}$ is known to possess many of the desired properties. However, there is very little data allowing direct comparison of its $\mathrm{Li}$ transference numbers with other candidates. Here, we report such a comparison obtained with the ENMR method (Table1). The samples have the same molar compositions but different salt. Also shown in the table is the molar weight of the salt and the measured salt molarity. The data shows a clear correlation between salt formula weight and $\mathrm{T}_{\mathrm{Li}}: \mathrm{T}_{\mathrm{Li}}$ increases with the size of the anions in both types of gel electrolytes. This trend is consistent with that in free solution electrolytes. The classic explanation for this is that as the anion mobility reduces with increasing anion size, the relative mobility of lithium escalates. The data supports the current endeavor by some researchers to seek lithium salt with even larger anion size, such as $\mathrm{LiC}\left(\mathrm{SO}_{2} \mathrm{CF}_{3}\right)_{3}$, as the salt for polymer electrolytes.

\section{Comparison Between PAN and Kynar Based Gel Electrolytes.}

Figure 1 shows the salt concentration dependence of $\mathrm{T}_{\mathrm{Li}}$ in PAN and Kynar gel electrolytes. Interestingly, $\mathrm{T}_{\mathrm{Li}}$ is seen to decrease in Kynar electrolytes but increase in PAN electrolytes. Table 2 shows the same trend with $\mathrm{PAN} / \mathrm{PC} / \mathrm{EC} / \mathrm{LiClO} 4$. The behavior of $\mathrm{TLi}$ in the Kynar electrolytes is similar to that in aqueous solution electrolytes (8), while its behavior in the PAN electrolytes is rather surprising.

Our hypothesis is that Kynar is indeed inert with no chemical interactions with either cations or anions. To zeroth order the polymer matrix acts an inert framework containing the solution and thus the polymer has no direct bearing on ionic mobility. Based on this assertion, adding Kynar to PC/salt solutions should not change the qualitative $\mathrm{T}_{\mathrm{Li}}$ behavior from that of salt solutions, which is what we observed here. Another test of the above hypothesis is to check the $\mathrm{TLi}_{\mathrm{Li}}$ at infinite dilution. $\mathrm{T}_{\mathrm{Li}}$ should be only weakly dependent on the type of solvent at infinite dilution, as complete ion dissociation is expected. At $\left[\mathrm{LiCF}_{3} \mathrm{SO}_{3}\right] \rightarrow 0$, our previous data show that $\mathrm{TLi} \rightarrow 0.5$ in $\mathrm{H}_{2} \mathrm{O}(5)$, and here as Figure 1 shows, $\mathrm{T}_{\mathrm{Li}} \rightarrow 0.5$ in Kynar electrolytes. The above analysis suggests a particularly simple mechanism for ion transport in Kynar gel electrolytes: the ion mobility is independent of the polymer chain mobility, and the 
Kynar gel electrolytes can be modeled as inter-connected "pockets" of electrolyte solutions separated by an inert matrix.

We suggest that the trends observed for the PAN gels are brought about by the interaction of lithium ions with the nitrile groups of the PAN gels. Such interactions have been proposed based on spectroscopic evidence. A recent paper by Wang et al (10) reported some IR and Raman evidence of strong interactions between $\mathrm{Li}^{+}$ions and nitrile groups of the PAN molecules in a sample with much higher salt concentrations than we used. Other workers have suggested weaker interactions. If $\mathrm{PAN}-\mathrm{Li}^{+}$ interactions are indeed non-negligible, the $\mathrm{T}_{\mathrm{Li}}$ data here suggests that such interactions affect $\mathrm{Li}$ transference numbers considerably: at infinite dilution, $\mathrm{T}_{\mathrm{Li}}$ is about 0.15 in $\mathrm{PAN} / \mathrm{PC} / \mathrm{EC} / \mathrm{LiCF}_{3} \mathrm{SO}_{3}$ compared to 0.5 in solutions or Kynar electrolytes.

The difference in the behavior of the transference number for the two types of gel electrolytes points to an important conclusion regarding structure-property relationships. The lithium transference number is typically lower for the interacting gel than for the non-interacting gel at low concentrations. This point is particularly important since most solid polymer electrolytes currently being used and synthesized exploit polymer-lithium interactions, which are essential to salt solubility in the electrolyte. Our results suggest that it may be a tricky proposition to achieve high transference numbers in such systems. However, our results do suggest that at higher concentration, some lithium ions are 'liberated' in the interacting gel and the $\mathrm{T} \mathrm{Li}$ increases substantially. Unfortunately, the conductivity of such gels is not as high as at lower concentrations.

The Effects of Ion-Ion Interactions on Transference Numbers.

To study the extent of ion association in the samples under study, we looked at the symmetric $\mathrm{SO}_{3}$ stretch in $\mathrm{PAN} / \mathrm{PC} / \mathrm{EC} / \mathrm{LiCF} \mathrm{SO}_{3}$ samples by Raman spectrocopy (Figure 2). Ferry et al (11) have shown that the presence of multiple bands in the spectral region shown in Figure 2 indicates lithium-triflate interactions perturbing the $\mathrm{SO}_{3}$ stretch. Clearly, such interactions are present at all concentrations. Besides the ion pairs, we can even see the onset of formation of higher order ion aggregates. Thus the possible equilibria include:

$$
\begin{aligned}
& \mathrm{MX} \Leftrightarrow=\mathrm{M}^{+}+\mathrm{X}^{-} \\
& 2 \mathrm{M}^{+}+\mathrm{X}^{-} \Leftrightarrow>\mathrm{M}_{2} \mathrm{X}^{+} \\
& \mathrm{M}^{+}+2 \mathrm{X}^{-} \Leftrightarrow=\mathrm{MX}_{2}
\end{aligned}
$$

The effects of ion triples on transference numbers can be complicated. However, taking two extreme cases, we can show easily that the formation of positive ion triples leads 
toa decrease in the lithium transference numbers, while formation of negative ion triples leads to increasing lithium transference numbers. Whether the formation of negative ion triples contributes to the increasing trend observed in PAN electrolytes needs further experimental and analytical investigation.

\section{CONCLUSIONS}

ENMR can be readily applied to polymer gel electrolytes. Its main advantages over the Hittorf method are its rapidity and higher accuracy. The validity of the ENMR method of transference number measurement is independent of the extent of ion association. The strong ion-ion interactions that are likely present in polymer electrolytes make many alternative methods invalid. Therefore, we expect the ENMR method to be an extremely valuable technique for polymer electrolytes characterization. Currently, ENMR studies of solid polymer electrolytes are ongoing in our laboratory.

With our unique capability to measure transference numbers in these gel electrolytes, we are able to investigate the dependence of transference numbers on anion size, salt concentrations and polymer types in polymer gel electrolytes. With the aid of vibrational spectroscopy, microscopic-level factors underlying such correlations may be found. The most interesting finding from this work is the effect of the presence of interacting groups in the PAN gels on the concentration dependence of the transference number.

\section{ACKNOWLEDGMENTS}

We wish to thank the US DOE Office of Transportation Technology for their support of this work. Hongli Dai is a graduate student in the Department of Chemical Engineering at the University of California, Santa Barbara, and he would like to thank Professor Eric W. McFarland of UCSB for helpful discussions. We also wish to thank $3 \mathrm{M}$ for their supply of the LiTFSI salt.

\section{REFERENCES}

1. F. Croce, F. Gerace, G. Dautzemberg, S. Passerini, G.B. Appetecchi, B. Scrosati, Electrochemica Acta., 39(14), 2187(1994).

2.H.S. Choe, J. Giaccai, M. Alamgir, K.M. Abraham, Electrochemica Acta., 40(13/14), 2289(1993).

3. P.G. Bruce and C.A. Vincent, Faraday Discuss. Chem. Soc., 43, 88(1989).

4. Olsen I., Koksbang R., Skou E., Electrochemica Acta.,40(11), 1701, 1995.

5. H. Dai, T. Zawodzinski Jr., J. of the Electrochem. Soc., 143(6), 107(1996). 
6. F. Croce, S. Brown, S. Greenbaum, S. Slane, M. Salomon, Chem. Mater., 5(9), 1268(1993).

7. T. Zawodzinski Jr., H. Dai, this Proceeding.

8. P. T. Callaghan, Principles of Nuclear Magnetic Resonance Microscopy, Clarenson Press, Oxford(1992).

9. Robinson, Stokes, Electrolyte solutions, p158, Butterworth(1959).

10. Wang Z, Huang B., Huang H., Chen L., Xue R., and Wang F, Electrochemica Acta., 41(9), 1443(1996).

11. Ferry A., Jacobsson P., Torell L., Electrochemica. Acta., 40(13), 2369(1995). 
Table 1. Effect of anion size on $\mathrm{T}_{\mathrm{Li}}\left(30^{\circ} \mathrm{C}\right)$

(a) PAN(16)/PC(23)/EC(56.5)/LiX(4.5)

\begin{tabular}{cccc}
\hline $\mathrm{X}^{-}$ & $\mathrm{FW} / \mathrm{LiX}$ & {$[\mathrm{LiX}]$} & $\mathrm{T}$ Li \\
\hline $\mathrm{ClO}_{4}^{-}$ & 106 & 0.63 & 0.13 \\
$\mathrm{CF}_{3} \mathrm{SO}_{3}^{-}$ & 156 & 0.60 & 0.23 \\
$\left(\mathrm{CF}_{3} \mathrm{SO}_{2}\right)_{2} \mathrm{~N}^{-}$ & 287 & 0.55 & 0.28 \\
\hline
\end{tabular}

(b) $\operatorname{Kynar(36.9)/PC(60)/LiX(3.1)~}$

\begin{tabular}{cccc}
\hline $\mathrm{X}^{-}$ & $\mathrm{FW} / \mathrm{LiX}$ & {$[\mathrm{LiX}]$} & $\mathrm{T}_{\mathrm{Li}}$ \\
\hline $\mathrm{CF}_{3} \mathrm{SO}_{3}{ }^{-}$ & 156 & 0.36 & 0.32 \\
& & & 0.39 \\
$\left(\mathrm{CF}_{3} \mathrm{SO}_{2}\right)_{2} \mathrm{~N}^{-}$ & 287 & 0.38 & \\
\hline
\end{tabular}

Table 2: $\mathrm{Li}$ transference numbers, $\mathrm{T}_{\mathrm{Li}}$, at $30^{\circ} \mathrm{C}$ in PAN/PC/EC/LiClO 4

\begin{tabular}{ccc}
\hline Samples w/molar compositions & {$\left[\mathrm{Li}^{+}\right](\mathrm{M})$} & $\mathrm{T}_{\mathrm{Li}}$ \\
\hline $\mathrm{PAN}(16) / \mathrm{PC}(23) / \mathrm{EC}(56.5) / \mathrm{LiClO}_{4}(4.5)$ & 0.63 & 0.13 \\
\hline $\mathrm{PAN}(16) / \mathrm{PC}(23) / \mathrm{EC}(56.5) / \mathrm{LiClO}_{4}(10.8)$ & 1.26 & 0.34 \\
\hline
\end{tabular}




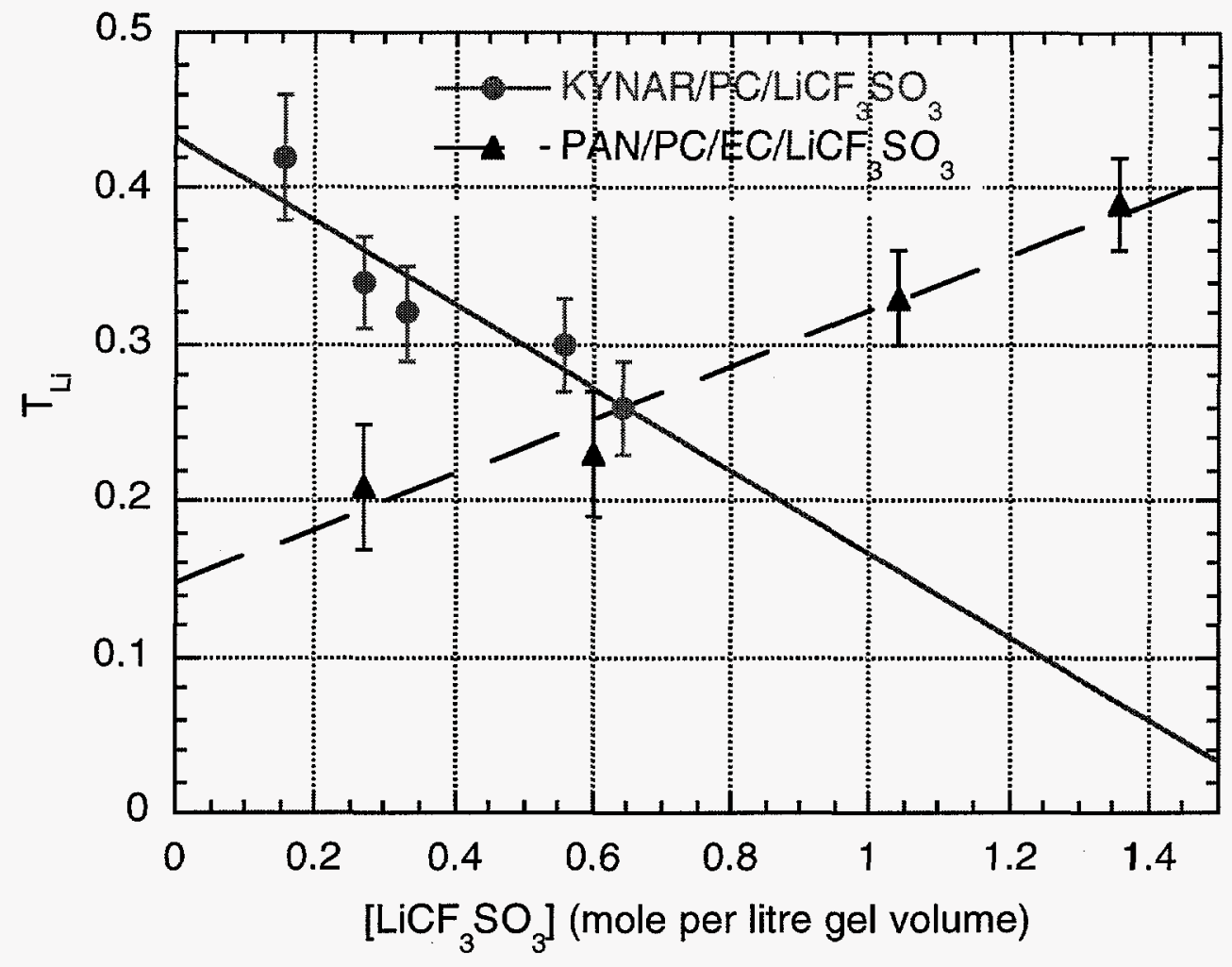

Fig 1. Salt concentration dependence of $\mathrm{T}_{\mathrm{Li}}$ in $\mathrm{PAN} / \mathrm{EC} / \mathrm{PC} / \mathrm{LiCF}_{3} \mathrm{SO}_{3}$ and $\mathrm{KYNAR} / \mathrm{PC} / \mathrm{Li}\left(\mathrm{CF}_{3} \mathrm{SO}_{2}\right)_{2} \mathrm{~N}$ gel electrolytes at $30^{\circ} \mathrm{C}$, as measured by ENMR. The solid lines are used to guide the eye, not to indicate any fitting. 


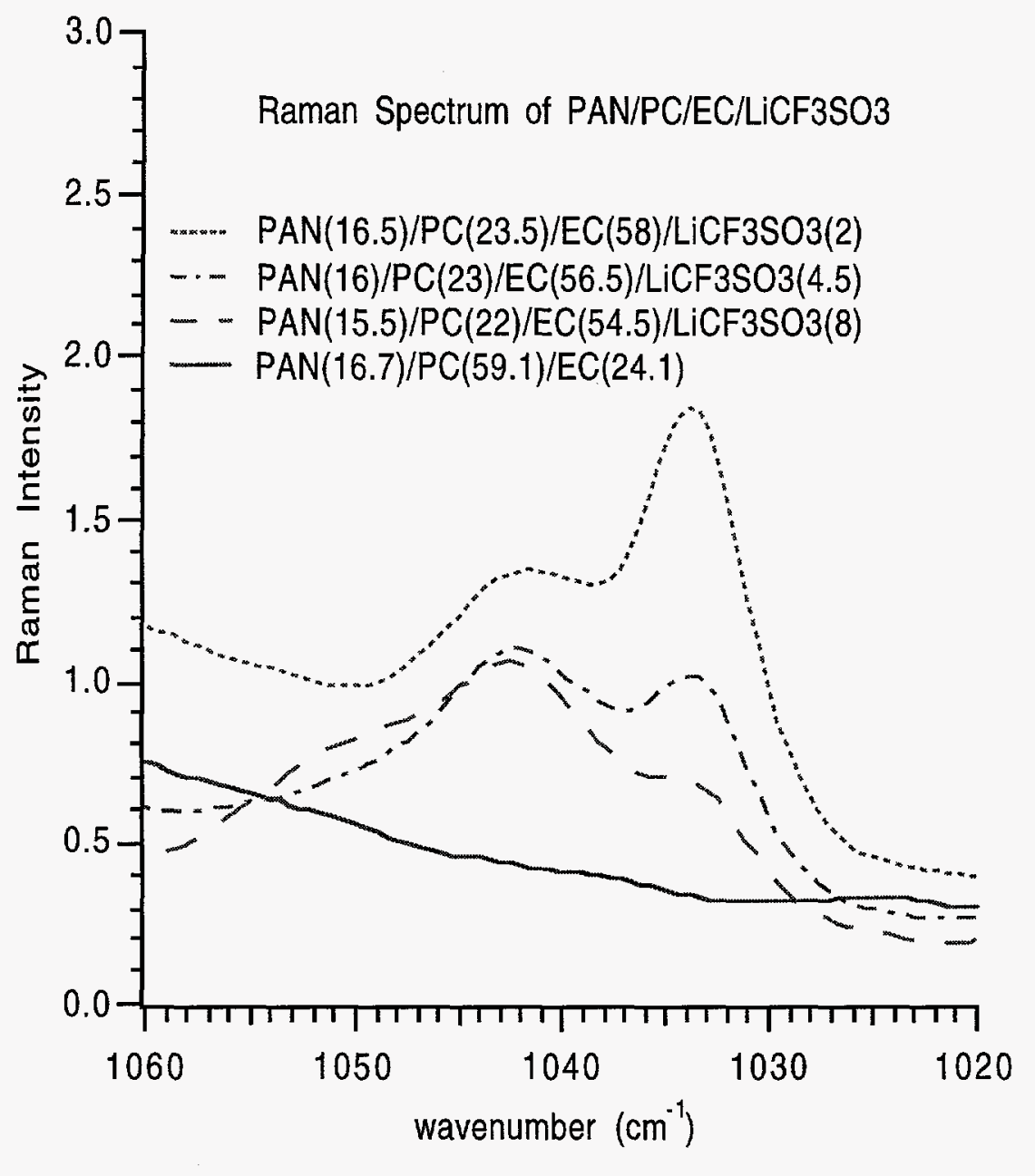

Figure 2: Raman spectrum: symmetric $\mathrm{SO}_{3}$ stretching region of PAN gel electrolytes with lithium triflate showing substantial ion associations at all concentrations studied. 